Article

\title{
Interaction Mechanism of Flavonoids and $\alpha$-Glucosidase: Experimental and Molecular Modelling Studies
}

\author{
Chengyun He ${ }^{1}$, Xiaoling Liu ${ }^{1}$, Zhaojing Jiang ${ }^{1}$, Sheng Geng ${ }^{2}$, Hanjun Ma ${ }^{1}$ and Benguo Liu ${ }^{1} * * \mathbb{C}$ \\ 1 School of Food Science, Henan Institute of Science and Technology, Xinxiang 453003, China \\ 2 Key Laboratory of Biorheological Science and Technology, Ministry of Education, School of Bioengineering, \\ Chongqing University, Chongqing 400044, China \\ * Correspondence: liubenguo@hist.edu.cn; Tel.: +86-158-3735-7870
}

Received: 23 July 2019; Accepted: 18 August 2019; Published: 21 August 2019

check for updates

\begin{abstract}
Flavonoids are known to play a role in hypoglycemia by inhibiting $\alpha$-glucosidase. However, their interaction mechanism with $\alpha$-glucosidase still needs to be elaborated. In this study, the $\alpha$-glucosidase inhibitory activities of 15 flavonoids were investigated. Their molecular volume had a negative effect on inhibitory activity, while the number of phenolic hydroxyl groups on the B ring was positively correlated with inhibitory activity. To explain the significant differences in activity, the interaction behaviors of myricetin and dihydromyricetin, which have similar structures, were compared by spectrofluorimetry, molecular docking, and the independent gradient model (IGM). In the fluorescence analysis, myricetin exhibited a higher binding capacity. Based on molecular docking and IGM analysis, their non-covalent interactions with $\alpha$-glucosidase could be visualized and quantified. It was found that they had different binding modes with the enzymes and that myricetin possessed stronger hydrogen bonding and van der Waals force interactions, which explained the thermodynamic results.
\end{abstract}

Keywords: flavonoids; $\alpha$-glucosidase; interaction; molecular docking; independent gradient model

\section{Introduction}

Diabetes mellitus is one of the most serious and chronic diseases characterized by hyperglycemia, which can lead to many complications including nephropathy, neuropathy, and cardiovascular diseases [1,2]. Today, its incidence is rising rapidly with the ageing population and increase in obesity. Its incidence is predicted to increase from $2.8 \%$ ( 171 million) in the year 2000 to $4.4 \%$ (366 million) by the year 2030 [3].

While diabetes places a burden on patients, its management and treatment costs have also become a huge burden on human society. It has been reported that type II diabetes accounts for more than $90 \%$ of diabetes cases, and postprandial blood glucose plays a key role in the development of type II diabetes and its complications [4]. One effective strategy for controlling postprandial hyperglycemia is to delay glucose absorption by using $\alpha$-glucosidase inhibitors [5]. Synthetic $\alpha$-glucosidase inhibitors (acarbose, miglitol, and voglibose) all have drawbacks such as hepatotoxicity and adverse gastrointestinal symptoms, which necessitate the search for safer and more effective alternatives [3].

In the past 20 years, plant-derived flavonoids have attracted extensive attention due to their various biological activities, including their antioxidant, antiviral, anti-inflammatory, anti-tumor, and anti-cardiovascular activities [6-8]. Flavonoids can regulate glucose absorption and homeostasis, with disaccharidases as targets. It has been reported that after two days of treatment with myricetin (3 mg/12 h), hyperglycemia in diabetic rats was reduced by 50\% [9]. Dihydromyricetin can improve 
skeletal muscle insulin resistance by inducing autophagy via the AMPK signaling pathway [10]. Many flavonoids, such as quercetin and kaempferol, have exhibited $\alpha$-glucosidase inhibitory activities [11,12]. Proenca et al. (2017) found that flavonoids with two catechol groups at the A or B ring and a hydroxy group at C3 possessed the highest $\alpha$-glucosidase inhibitory activity [13]. The absence of a double bond between $\mathrm{C} 2$ and $\mathrm{C} 3$ and a ketonic group at $\mathrm{C} 4$ significantly reduces the $\alpha$-glucosidase inhibitory activity of flavonoids [14].

Flavonoids exert their $\alpha$-glucosidase inhibitory activities by forming complexes with enzymes through non-covalent interactions [15]. During this process, the enzyme molecules undergo structural changes and energy transfer, which can be detected by common experimental methods (fluorescent spectrometry, circular dichroism, isothermal titration calorimetry, surface plasmon resonance, etc.) [16-18]. However, these complicated measurement conditions introduce great difficulties into the experimental design and analysis, and most of the experimental technologies have failed to obtain a detailed structure of the complexes and to quantitatively visualize the non-covalent interactions.

In recent years, computational methods have gradually become important research tools. Molecular simulation methods such as ONIOM calculations, molecular dynamics, and molecular docking have been widely used to study the binding modes and energies of bioactive compounds and enzymes. Zeng et al. (2016) investigated the binding modes of two isoflavones (daidzein and genistein) with trypsin using molecular docking methods [19]. Li et al. (2009) clarified the interaction mechanism of the cyclin-dependent kinases (CDK2 and CDK4) and their inhibitor (2PU) based on ONIOM calculations [20]. In 2017, Lefebvre et al. presented a new approach, the independent gradient model (IGM), which enabled the automatic identification and visualization of covalent and non-covalent interactions of atoms/fragments in the 3D real space using pro-molecular density [21].

In this study, the $\alpha$-glucosidase inhibitory activity of 15 flavonoids from edible plant-derived foods were compared. Then, the interaction behaviors of myricetin and dihydromyricetin with $\alpha$-glucosidase were investigated by spectrofluorimetry. The underlying interaction mechanism was also clarified based on the molecular docking and IGM methods.

\section{Materials and Methods}

\subsection{Materials and Chemicals}

The 15 flavonoids (myricetin, fisetin, quercetin, baicalein, luteolin, isoliquiritigenin, chrysin, dihydromyricetin, 4-hydroxychalcone, $4^{\prime}$-hydroxychalcone, hesperetin, naringin, hesperidin, baicalin, rutin) and acarbose were purchased from Aladdin (Shanghai, China). $\alpha$-Glucosidase from Saccharomyces cerevisiae and p-nitrophenyl- $\alpha$-D-glucopyranoside (pNP-G) were the products of Sigma-Aldrich (St. Louis, MO, USA). The ultrapure water was obtained from a Thermo Gen Pure UV/UF water system (Waltham, MA, USA).

\section{2. $\alpha$-Glucosidase Inhibitory Assay}

The $\alpha$-glucosidase inhibitory activity of the flavonoids was determined according to the methods described in a previous report [22]. The substrate, pNP-G, can be hydrolyzed by $\alpha$-glucosidase to p-nitrophenyl (pNP), with a maximum absorbance peak at $405 \mathrm{~nm}$. For the inhibition assay, the $\alpha$-glucosidase, pNP-G, and flavonoids were dissolved in a phosphate buffer $(0.1 \mathrm{M}, \mathrm{pH}$ 6.8), then $1 \mathrm{~mL}$ of each flavonoid at different concentrations and $1 \mathrm{~mL}$ of $0.2 \mathrm{U} / \mathrm{mL} \alpha$-glucosidase solution were mixed and incubated at $37^{\circ} \mathrm{C}$ for $10 \mathrm{~min}$. Next, $1 \mathrm{~mL}$ of a $1 \mathrm{mM}$ pNP-G solution was added. The obtained mixture was kept at $37^{\circ} \mathrm{C}$ for $20 \mathrm{~min}$. Then, $1 \mathrm{~mL}$ of ethanol was added to terminate the reaction. The absorbance of the mixture at $405 \mathrm{~nm}\left(\mathrm{~A}_{\text {sample }}\right)$ was measured using a UNICO 7200 spectrophotometer (Shanghai, China). The absorbance of the mixture containing PBS instead of a flavonoid was also read as the $\mathrm{A}_{\text {control }}$. The $\alpha$-glucosidase inhibitory activity of the flavonoids was calculated by Equation (1):

$$
\alpha-\text { Glucosidase inhibitory activity }=\frac{\mathrm{A}_{\text {control }}-\mathrm{A}_{\text {sample }}}{\mathrm{A}_{\text {control }}} \times 100 \%
$$




\subsection{Determination of Interaction Behaviors of Myricetin and Dihydromyricetin}

To clarify the $\alpha$-glucosidase inhibitory mechanism of flavonoids, myricetin and dihydromyricetin were selected for fluorescence measurement. They have similar structures but exhibit very different $\alpha$-glucosidase inhibitory activities. The fluorescence spectra of $\alpha$-glucosidase in the presence of myricetin or dihydromyricetin at different concentrations and at 25 or $30{ }^{\circ} \mathrm{C}$ were recorded by an Agilent Cary Eclipse fluorescence spectrophotometer (Santa Clara, CA, USA), with the excitation and emission slits set at $5 \mathrm{~nm}$. The excitation wavelength was set at $280 \mathrm{~nm}$, while the range of the emission wavelength was $300-440 \mathrm{~nm}$.

\subsection{Molecular Docking Method}

The 3D structure of the $\alpha$-glucosidase from Saccharomyces cerevisiae (PDB, 3A4A) was downloaded from the RSCB protein databank (http://www.rcsb.org). Before docking, the structure of the $\alpha$-glucosidase was prepared by removing the water and ligands, adding polar hydrogen and charge, and repairing residues. The chemical structures of myricetin and dihydromyricetin were established and optimized using MOPAC 2016 and employing a semiempirical PM6 method [23]. By using Autodock 4.2 software [24], myricetin and dihydromyricetin were docked into the active site based on the binding mode of maltose to the enzyme by the Lamarckian genetic algorithm method. The grid spacing was set at $0.375 \AA$, and all of the points of the grid box in the $x, y$, and $z$ directions were 60. During docking, the rigid structure of the $\alpha$-glucosidase was maintained while the structure of the flavonoid was regarded as fully flexible. Then, the complex with the lowest binding energy was selected and analyzed to obtain a schematic diagram of the interaction between the flavonoid and $\alpha$-glucosidase by using LigPlot+ v.2.1 software [25].

\subsection{IGM Method}

For the IGM analysis, the PDB file containing the molecular docking result was imported into the Multiwfn 3.6(dev) software [26]. The flavonoid and $\alpha$-glucosidase were defined as fragments. The whole system was also covered by a high-quality grid (approximately 1,728,000 points in total). Then, Multiwfn started to calculate the density gradient of atoms $\left(\delta_{\mathrm{g}}\right)$, the electron density, and the sign of the second Hessian eigenvalue in Laplacians $\operatorname{sign}\left(\lambda_{2}\right) p$ in real space based on the pro-molecular density. The obtained $\delta_{\mathrm{g}}$ could be separated into $\delta_{\text {ginter }}$ and $\delta_{\text {gintra }}$, representing the interfragment and intrafragment interactions, respectively. Based on these grid data, the non-covalent interactions between the flavonoid and $\alpha$-glucosidase could be visualized and quantified using VMD software [27].

\subsection{Statistical Analysis}

The $\alpha$-glucosidase inhibitory assay was carried out based on three independent experiments. Statistical comparisons were performed using the t-test. A $p$ value of $<0.05$ was considered to be a significant difference.

\section{Results and Discussion}

\section{1. $\alpha$-Glucosidase Inhibitory Activities}

As shown in Table 1 , the $\alpha$-glucosidase inhibitory activities of the 15 flavonoids were compared. A significant effect of the chemical structures of flavonoids on their inhibitory activity was found. The preliminary structure-activity relationship (SAR) was summarized as follows: (1) Compared with the flavonoid aglycones (Compounds 1-10), the flavonoid glycosides (Compounds 11-15) exhibited poor inhibitory activity; (2) for the flavonoid aglycones, the number of phenolic hydroxyl groups on their B ring had a positive effect on their inhibitory activity. The former might be due to the large molecular size of flavonoid glycosides, which hindered their access to the enzyme. The latter could be explained by the $B$ ring of flavonoids pointing to the inside of the active center of the enzyme, which is an important 
site for their binding with the enzyme. A strange phenomenon was also observed in that, although myricetin and dihydromyricetin had similar structures, they differed in their inhibitory activity by more than 40 times, which could not be explained solely by the difference in molecular volume and the number of phenolic hydroxyl groups on their B ring. Therefore, myricetin and dihydromyricetin were selected for further study.

Table 1. The chemical structures and $\mathrm{IC}_{50}$ values $(\mu \mathrm{g} / \mathrm{mL})$ of 15 flavonoids.

\begin{tabular}{|c|c|c|c|c|c|c|c|c|c|c|c|c|}
\hline & & $\begin{array}{l}\|_{\mathrm{O}} 4 \\
\mathrm{I}\end{array}$ & & & & & & & III & & & \\
\hline No. & Type & Name & 3 & 4 & 5 & 6 & 7 & $2^{\prime}$ & $3^{\prime}$ & $4^{\prime}$ & $5^{\prime}$ & $\mathrm{IC}_{50}$ \\
\hline 1 & I & myricetin & $\mathrm{OH}$ & & $\mathrm{OH}$ & & $\mathrm{OH}$ & & $\mathrm{OH}$ & $\mathrm{OH}$ & $\mathrm{OH}$ & 2.09 \\
\hline 2 & I & fisetin & $\mathrm{OH}$ & & & & $\mathrm{OH}$ & & $\mathrm{OH}$ & $\mathrm{OH}$ & & 5.50 \\
\hline 3 & I & quercetin & $\mathrm{OH}$ & & $\mathrm{OH}$ & & $\mathrm{OH}$ & & $\mathrm{OH}$ & $\mathrm{OH}$ & & 6.10 \\
\hline 4 & I & baicalein & & & $\mathrm{OH}$ & $\mathrm{OH}$ & $\mathrm{OH}$ & & & & & 6.75 \\
\hline 5 & I & luteolin & & & $\mathrm{OH}$ & & $\mathrm{OH}$ & & $\mathrm{OH}$ & $\mathrm{OH}$ & & 27.22 \\
\hline 6 & III & isoliquiritigenin & & $\mathrm{OH}$ & & & & $\mathrm{OH}$ & & $\mathrm{OH}$ & & 36.29 \\
\hline 7 & $\mathrm{I}$ & chrysin & & & $\mathrm{OH}$ & & $\mathrm{OH}$ & & & & & 70.07 \\
\hline 8 & II & dihydromyricetin & $\mathrm{OH}$ & & $\mathrm{OH}$ & & $\mathrm{OH}$ & & $\mathrm{OH}$ & $\mathrm{OH}$ & $\mathrm{OH}$ & 85.95 \\
\hline 9 & III & 4-hydroxychalcone & & $\mathrm{OH}$ & & & & & & & & 123.04 \\
\hline 10 & III & $4^{\prime}$-hydroxychalcone & & & & & & & & $\mathrm{OH}$ & & 199.10 \\
\hline 11 & II & hesperetin & & & $\mathrm{OH}$ & & $\mathrm{OH}$ & & $\mathrm{OH}$ & $\mathrm{OCH} 3$ & & 286.60 \\
\hline 12 & II & naringin & & & $\mathrm{OH}$ & & O-Rut & & & $\mathrm{OH}$ & & $>500$ \\
\hline 13 & II & hesperidin & & & $\mathrm{OH}$ & & O-Rut & & $\mathrm{OH}$ & $\mathrm{OCH} 3$ & & $>500$ \\
\hline 14 & I & baicalin & & & $\mathrm{OH}$ & $\mathrm{OH}$ & O-Glu & & & & & $>500$ \\
\hline 15 & I & rutin & O-Rut & & $\mathrm{OH}$ & & $\mathrm{OH}$ & & $\mathrm{OH}$ & $\mathrm{OH}$ & & $>500$ \\
\hline
\end{tabular}

(Rut, rutinoside; Glu, glucuronide).

\subsection{Fluorescence Analysis}

In this study, the interactions of myricetin and dihydromyricetin with $\alpha$-glucosidase were systematically investigated by spectrofluorimetry [28]. In Figure 1, with the addition of the flavonoid, the intrinsic fluorescence of $\alpha$-glucosidase at 25 and $30{ }^{\circ} \mathrm{C}$ gradually decreased. The corresponding quenching rate constant $\left(\mathrm{K}_{\mathrm{q}}\right)$ could be calculated based on the following Stern-Volmer equation:

$$
\mathrm{F}_{0} / \mathrm{F}=1+\mathrm{K}_{\mathrm{sv}}[\mathrm{Q}]=1+\mathrm{K}_{\mathrm{q}} \tau_{0}[\mathrm{Q}],
$$

where $\mathrm{F}_{0}$ and $\mathrm{F}$ are the peak fluorescence intensities of $\alpha$-glucosidase in the absence and presence of the flavonoid; [Q] is the concentration of the flavonoid; and $\tau_{0}$ is the average life of the proteins $\left(10^{-8} \mathrm{~s}\right)$.

In Table 2, the $\mathrm{K}_{\mathrm{q}}$ values of both myricetin and dihydromyricetin were higher than the maximum $\mathrm{K}_{\mathrm{q}}$ value for dynamic quenching $\left(2 \times 10^{10} \mathrm{~L} \cdot \mathrm{mol}^{-1} \cdot \mathrm{s}^{-1}\right)$, indicating that they caused fluorescence quenching by a static quenching mechanism; that is, by forming complexes with the enzyme. Then, a double-logarithm Equation (3) was applied to obtain the corresponding binding constant $\left(\mathrm{K}_{\mathrm{a}}\right)$ and binding site number $(n)$ (Table 2):

$$
\lg \left[\left(\mathrm{F}_{0}-\mathrm{F}\right) / \mathrm{F}\right]=\lg \mathrm{K}_{\mathrm{a}}+n \lg [\mathrm{Q}] .
$$

For myricetin and dihydromyricetin, their binding site numbers with $\alpha$-glucosidase were near 1 , which suggests that they interacted with the enzyme at a molar ratio of 1:1. As the temperature increased, their binding constants decreased, because the increased temperature was able to destroy the non-covalent interaction and reduce the stability of the complex. 

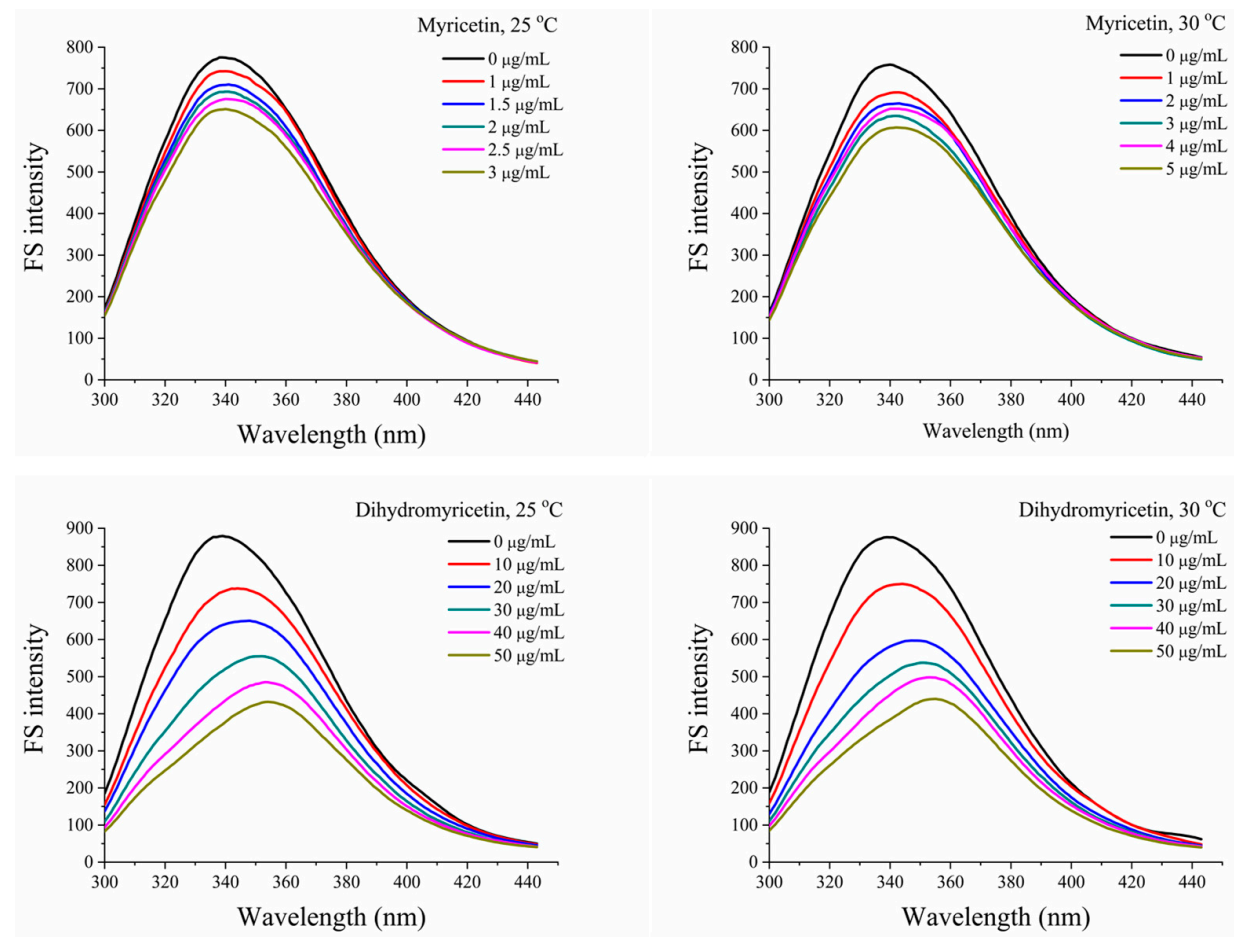

Figure 1. Effects of myricetin and dihydromyricetin on the fluorescence spectra of $\alpha$-glucosidase at 25 and $30{ }^{\circ} \mathrm{C}$ (FS: Fluorescence Spectrum).

Table 2. The quenching constants, binding constants, and thermodynamic parameters between two flavonoids and $\alpha$-glucosidase at 298 and $303 \mathrm{~K}$.

\begin{tabular}{|c|c|c|c|c|c|c|c|}
\hline Flavonoids & $\mathrm{T}(\mathrm{K})$ & $\begin{array}{c}10^{12} \mathrm{~K}_{\mathrm{q}} \\
\left(\mathrm{L} \cdot \mathrm{mol}^{-1} \cdot \mathrm{s}^{-1}\right)\end{array}$ & $\begin{array}{c}10^{4} \mathrm{~K}_{\mathrm{a}} \\
\left(\mathrm{L} \cdot \mathrm{mol}^{-1}\right)\end{array}$ & $n$ & $\begin{array}{c}\Delta \mathrm{G} \\
\left(\mathrm{KJ} \cdot \mathrm{mol}^{-1}\right)\end{array}$ & $\begin{array}{c}\Delta \mathrm{H} \\
\left(\mathrm{KJ} \cdot \mathrm{mol}^{-1}\right)\end{array}$ & $\begin{array}{c}\Delta \mathrm{S} \\
\left(\mathrm{J} \cdot \mathrm{mol}^{-1} \cdot \mathrm{K}^{-1}\right)\end{array}$ \\
\hline \multirow{2}{*}{ Myricetin } & 298 & 9.6733 & 7.7786 & 0.9843 & -27.91 & \multirow{2}{*}{-156.15} & \multirow[b]{2}{*}{-430.33} \\
\hline & 303 & 5.9984 & 2.7428 & 0.9386 & -25.76 & & \\
\hline \multirow{2}{*}{ Dihydromyricetin } & 298 & 3.1750 & 5.7637 & 1.0572 & -27.16 & \multirow{2}{*}{-115.61} & \multirow{2}{*}{-296.81} \\
\hline & 303 & 3.4092 & 2.6546 & 0.9764 & -25.68 & & \\
\hline
\end{tabular}

To determine the non-covalent interaction types, the thermodynamic parameters (enthalpy change, $\Delta \mathrm{H}$; entropy change, $\Delta S$; free-energy change, $\Delta \mathrm{G}$ ) were calculated by Equations (4)-(6):

$$
\begin{aligned}
\ln \frac{\mathrm{K}_{\mathrm{a} 2}}{\mathrm{~K}_{\mathrm{a} 1}} & =\frac{\Delta \mathrm{H}}{\mathrm{R}}\left(\frac{1}{\mathrm{~T}_{1}}-\frac{1}{\mathrm{~T}_{2}}\right) \\
\Delta \mathrm{G} & =-\mathrm{R} \ln \mathrm{K}_{\mathrm{a}} \\
\Delta \mathrm{S} & =\frac{\Delta \mathrm{H}-\Delta \mathrm{G}}{\mathrm{T}}
\end{aligned}
$$

As shown in Table 2, both of the $\Delta \mathrm{G}$ values were negative, indicating that the binding of myricetin and dihydromyricetin with $\alpha$-glucosidase was a spontaneous process. The corresponding $\Delta \mathrm{H}$ and $\Delta S$ values were also negative. According to a previous report [29], $\Delta \mathrm{H}>0$ and $\Delta S>0$ meant that the hydrophobic interaction is the main force, and $\Delta \mathrm{H}<0$ and $\Delta \mathrm{S}<0$ implied that hydrogen bonding and van der Waals forces played the primary role, while $\Delta \mathrm{H}<0$ and $\Delta \mathrm{S}>0$ suggested that electrostatic forces were driving the binding. It could be concluded that the complexes of myricetin and dihydromyricetin with $\alpha$-glucosidase were maintained by hydrogen bonding and van der Waals forces.

\subsection{Molecular Docking Analysis}

The molecular docking method has been widely applied to investigate the binding modes between enzymes and inhibitors $[30,31]$. To clarify the significant differences between myricetin and 
dihydromyricetin in terms of their $\alpha$-glucosidase inhibitory activity, their 3D binding modes with $\alpha$-glucosidase (Figure 2A1,A2) were established by using Autodock 4.2 software. It was found that the active center of $\alpha$-glucosidase was located inside the enzyme molecule. As a result, when the flavonoid glycosides with a larger molecular volume entered, the steric hindrance to be overcome was greater than that of flavonoid aglycones, so the inhibitory performance of flavonoid glycosides was generally lower. Figure 2B1,B2 shows the schematic diagrams of the interactions between flavonoids and $\alpha$-glucosidase. The equivalent residues have a red underlay beneath their bonds and atoms. It was found that: (1) Asp 215 was involved in the hydrogen-bonding interaction between each flavonoid with the enzyme; and (2) Tyr 72, Tyr 158, Phe 159, Phe 178, Asp 352, and Arg 442 had hydrophobic interactions with both myricetin and dihydromyricetin. Although the structures of myricetin and dihydromyricetin only differed in the bond types between C2 and C3, their hydrogen-bonding interactions with $\alpha$-glucosidase were quite different. Dihydromyricetin could form hydrogen-bonding interactions with more amino acid residues (Asp 69, Asp 215, Glu 277, His 280), but the average length of the hydrogen bonds was only $2.84 \AA$, which was significantly inferior to that of myricetin $(2.74 \AA)$, and it lacked hydrogen bonding in the zone around C5. The corresponding lowest binding energies for myricetin $(-9.6 \mathrm{kcal} / \mathrm{mol})$ and dihydromyricetin $(-9.56 \mathrm{kcal} / \mathrm{mol})$ were very close. Therefore, it was difficult to directly determine which flavonoid had the stronger binding capacity. Other theoretical methods are needed to quantitatively compare their interactions with $\alpha$-glucosidase based on the molecular docking results.
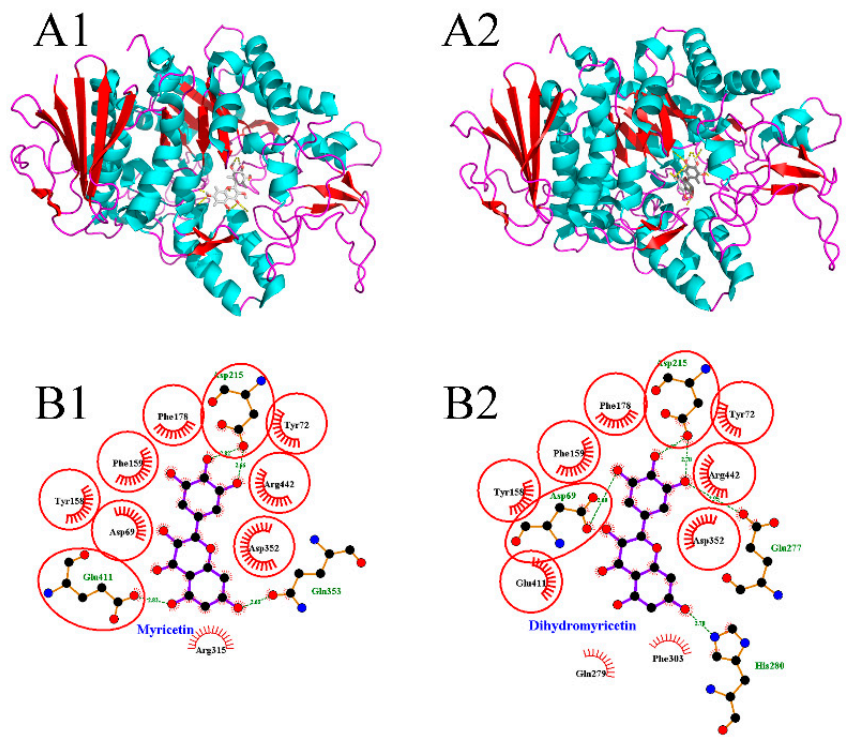

Figure 2. Molecular docking results of myricetin and dihydromyricetin with $\alpha$-glucosidase ((A1,A2) are the binding modes of myricetin and dihydromyricetin with $\alpha$-glucosidase, respectively; (B1,B2) are the schematic diagrams of the interactions between myricetin and dihydromyricetin with $\alpha$-glucosidase, respectively).

\subsection{IGM Analysis}

The visualization and quantification of the interaction based on IGM is a new development in molecular simulations [21]. The $\delta_{\mathrm{g}}$ is a key function in the IGM analysis framework; it is designed to reveal interactive regions between two (or even more) fragments. It can be separated into $\delta_{\text {ginter }}$ and $\delta_{\text {gintra }}$, which can reflect the interfragment and intrafragment interactions, respectively. Figure 3 simultaneously shows the scatter graphs of $\delta_{\text {ginter }}$ and $\delta_{\text {gintra }}$ vs. $\operatorname{sign}\left(\lambda_{2}\right) p$, in which the red and black points correspond to $\delta_{\text {ginter }}$ and $\delta_{\text {gintra }}$, respectively. In Figure $3 \mathrm{~A} 1, \mathrm{~A} 2$, there is a very prominent black peak of $\delta_{\text {gintra }}$ around $\operatorname{sign}\left(\lambda_{2}\right) p=-0.3$, representing the strong intrafragment covalent-bonding interactions. In the region where $\operatorname{sign}\left(\lambda_{2}\right) p$ is about $-0.04, \delta_{\text {ginter }}$ has a remarkable red peak with a height of approximately 0.03 , which implies the existence of hydrogen bonding [21]. In the region where 
$\operatorname{sign}\left(\lambda_{2}\right) p$ is approximately +0.02 , there is also a small red peak of $\delta_{\text {ginter }}$. Since a positive $\operatorname{sign}\left(\lambda_{2}\right) p$ implies a repulsive interaction, the peak could reflect weak steric regions between the flavonoid and $\alpha$-glucosidase. For myricetin, there are more red points around the $\operatorname{sign}\left(\lambda_{2}\right) p$ of -0.04 , indicating its stronger hydrogen-bonding interaction with $\alpha$-glucosidase.

A1

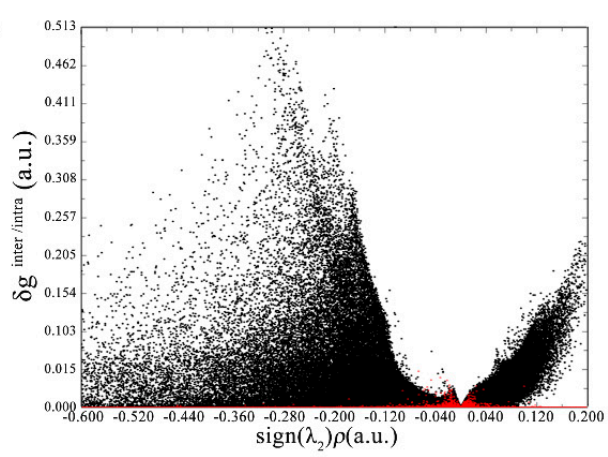

A2

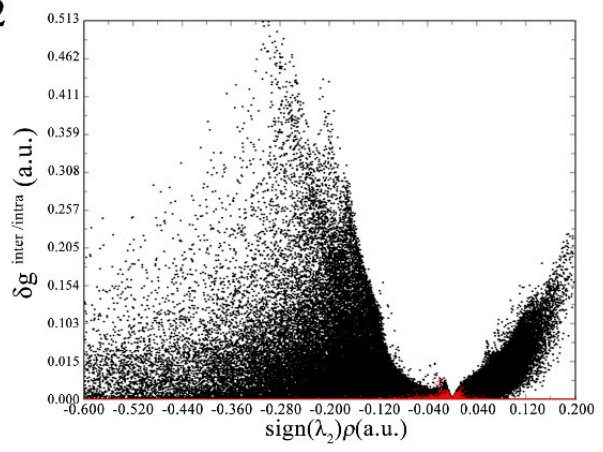

Figure 3. Visual scatter maps between $\delta_{\text {ginter }}$ and $\delta_{\text {gintra }}$ vs. $\operatorname{sign}\left(\lambda_{2}\right) p$ of myricetin (A1) and dihydromyricetin (A2) with $\alpha$-glucosidase.

By exporting the grid data of $\operatorname{sign}\left(\lambda_{2}\right) p, \delta_{\mathrm{g}}$, and $\delta_{\text {ginter }}$ to the VMD program, the color-filled $\delta_{\text {ginter }}$ isosurfaces could be drawn. Figure $4 \mathrm{~A}, \mathrm{~B}$ show the $\delta_{\text {ginter }}$ isosurfaces at the isovalues of 0.001 and 0.01 for myricetin and dihydromyricetin, respectively. The color transition was blue-green-red. The more blue the isosurface was, the stronger the attractive interaction; however, the more red the isosurface was, the larger the steric effect. A green zone in an isosurface indicates van der Waals interactions. As shown in Figure 4A1,A2, both myricetin and dihydromyricetin were surrounded by blue and green zones, indicating that the main interaction was due to hydrogen bonding and van der Waals forces; these observations agreed well with the thermodynamic results of fluorescence analysis. It was also found that myricetin was completely encompassed by the isosurface at an isovalue of 0.001 , while dihydromyricetin was encircled except for $\mathrm{C} 5$ and $\mathrm{C} 6$. The absence of the interaction at $\mathrm{C} 5$ and $\mathrm{C} 6$ was consistent with the molecular docking results. When the isosurface was set at 0.01 (Figure 4B1,B2), the interaction zone of myricetin was still significantly larger than that of dihydromyricetin. It could be concluded that the binding capacity of myricetin with $\alpha$-glucosidase is superior to that of dihydromyricetin. As a result, its $\alpha$-glucosidase inhibitory activity is higher than that of dihydromyricetin.

A1

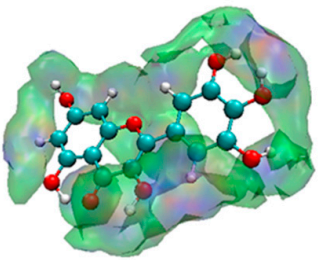

B1

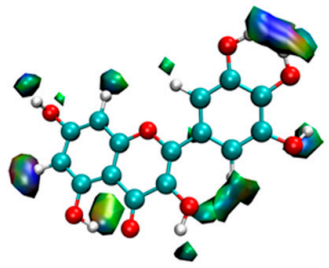

A2

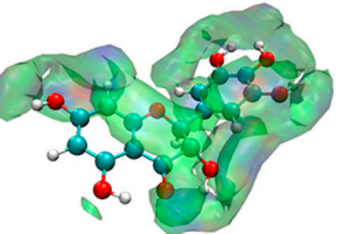

B2

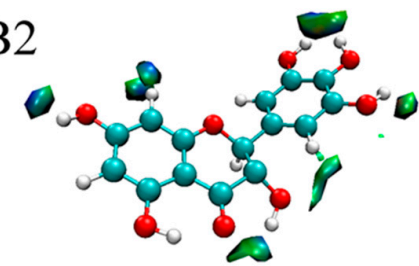

Figure 4. Visual weak interactions of myricetin and dihydromyricetin with $\alpha$-glucosidase ((A1,A2) are the color-filled $\delta_{\text {ginter }}$ isosurfaces around myricetin and dihydromyricetin at an isovalue of 0.001 , respectively; (B1,B2) are the color-filled $\delta_{\text {ginter }}$ isosurfaces around myricetin and dihydromyricetin at the isovalue of 0.01 , respectively). 


\section{Conclusions}

In this study, the $\alpha$-glucosidase inhibitory activities of 15 common flavonoids were compared. The inhibitory performance of the flavonoid aglycones was significantly superior to that of the flavonoid glycosides. A positive relationship between the number of phenolic hydroxyl groups in the $\mathrm{B}$ ring of flavonoids and the activity was also determined. Myricetin and dihydromyricetin had similar structures, but the inhibitory activity of myricetin was significantly higher than that of dihydromyricetin. In the fluorescence analysis, myricetin also showed a higher binding capacity with $\alpha$-glucosidase. To clarify the underlying mechanism, a molecular simulation of myricetin and dihydromyricetin was carried out. The molecular docking results suggested that they had different orientations in the active center of $\alpha$-glucosidase. Myricetin exhibited stronger hydrogen bonding and van der Waals force interactions according to the IGM analysis, which was in agreement with the thermodynamic parameters. The results obtained in this study should prompt the application of flavonoids as hypoglycemic nutraceuticals. The proposed method of combining IGM with molecular docking analysis provides a convenient way to investigate the interaction between polyphenols and proteins.

Author Contributions: Conceptualization, B.L. and C.H.; Methodology, B.L. and C.H.; Software, B.L. and S.G.; Validation, C.H., X.L., and Z.J.; Formal Analysis, C.H. and X.L.; Investigation, B.L.; Resources, H.M.; Data Curation, S.G.; Writing-Original Draft Preparation, B.L. and C.H.; Writing-Review and Editing, H.M.; Visualization, Z.J.; Supervision, B.L.; Project Administration, B.L.; Funding Acquisition, B.L. and H.M.

Funding: This research was funded by the National Natural Science Foundation of China, grant numbers 31771941 and 31571912 .

Conflicts of Interest: The authors declare no conflict of interest.

\section{References}

1. Liu, L.; Deseo, M.A.; Morris, C.; Winter, K.M.; Leach, D.N. Investigation of $\alpha$-glucosidase inhibitory activity of wheat bran and germ. Food Chem. 2011, 126, 553-561. [CrossRef]

2. Zimmet, P.; Alberti, K.; Shaw, J. Global and societal implications of the diabetes epidemic. Nature 2001, 414, 782-787. [CrossRef] [PubMed]

3. Ghani, U. Re-exploring promising $\alpha$-glucosidase inhibitors for potential development into oral anti-diabetic drugs: Finding needle in the haystack. Eur. J. Med. Chem. 2015, 103, 133-162. [CrossRef] [PubMed]

4. Alongi, M.; Anese, M. Effect of coffee roasting on in vitro $\alpha$-glucosidase activity: Inhibition and mechanism of action. Food Res. Int. 2018, 111, 480-487. [CrossRef] [PubMed]

5. Kadouh, H.C.; Sun, S.; Zhu, W.; Zhou, K. $\alpha$-Glucosidase inhibiting activity and bioactive compounds of six red wine grape pomace extracts. J. Funct. Foods 2016, 26, 577-584. [CrossRef] [PubMed]

6. Erlund, I. Review of the flavonoids quercetin, hesperetin, and naringenin. Dietary sources, bioactivities, bioavailability, and epidemiology. Nutr. Res. 2004, 24, 851-874. [CrossRef]

7. Wang, T.Y.; Li, Q.; Bi, K.S. Bioactive flavonoids in medicinal plants: Structure, activity and biological fate. Asian J. Pharm. Sci. 2018, 13, 12-23. [CrossRef]

8. Yang, B.; Liu, H.; Yang, J.; Gupta, V.K.; Jiang, Y. New insights on bioactivities and biosynthesis of flavonoid glycosides. Trends Food Sci. Technol. 2018, 79, 116-124. [CrossRef]

9. Ong, K.C.; Khoo, H.E. Effects of myricetin on glycemia and glycogen metabolism in diabetic rats. Life Sci. 2000, 67, 1695-1705. [CrossRef]

10. Shi, L.Y.; Zhang, T.; Liang, X.Y.; Hu, Q.; Huang, J.; Zhou, Y.; Chen, M.L.; Zhang, Q.Y.; Zhu, J.D.; Mi, M.T. Dihydromyricetin improves skeletal muscle insulin resistance by inducing autophagy via the AMPK signaling pathway. Mol. Cell. Endocrinol. 2015, 409, 92-102. [CrossRef]

11. Li, Y.Q.; Zhou, F.C.; Gao, F.; Bian, J.S.; Shan, F. Comparative evaluation of quercetin, isoquercetin and rutin as inhibitors of $\alpha$-glucosidase. J. Agric. Food Chem. 2009, 57, 11463-11468. [CrossRef] [PubMed]

12. Peng, X.; Zhang, G.; Liao, Y.; Gong, D. Inhibitory kinetics and mechanism of kaempferol on $\alpha$-glucosidase. Food Chem. 2016, 190, 207-215. [CrossRef] [PubMed] 
13. Proença, C.; Freitas, M.; Ribeiro, D.; Oliveira, E.F.; Sousa, J.L.; Tomé, S.M.; Ramos, M.J.; Silva, A.M.; Fernandes, P.A.; Fernandes, E. $\alpha$-Glucosidase inhibition by flavonoids: $A n$ in vitro and in silico structure-activity relationship study. J. Enzym. Inhib. Med. Chem. 2017, 32, 1216-1228. [CrossRef] [PubMed]

14. Sarian, M.N.; Ahmed, Q.U.; So'ad, M.; Zaiton, S.; Alhassan, A.M.; Murugesu, S.; Perumal, V.; Mohamad, S.; Akilah, S.N.; Khatib, A. Antioxidant and antidiabetic effects of flavonoids: A structure-activity relationship based study. BioMed Res. Int. 2017, 2017, 8386065. [CrossRef] [PubMed]

15. Zhang, B.W.; Li, X.; Sun, W.L.; Xing, Y.; Xiu, Z.L.; Zhuang, C.L.; Dong, Y.S. Dietary flavonoids and acarbose synergistically inhibit $\alpha$-glucosidase and lower postprandial blood glucose. J. Agric. Food Chem. 2017, 65, 8319-8330. [CrossRef] [PubMed]

16. Liu, X.; Luo, F.; Li, P.; She, Y.; Gao, W. Investigation of the interaction for three Citrus flavonoids and $\alpha$-amylase by surface plasmon resonance. Food Res. Int. 2017, 97, 1-6. [CrossRef] [PubMed]

17. Sadeghi-Kaji, S.; Shareghi, B.; Saboury, A.A.; Farhadian, S. Spectroscopic and molecular docking studies on the interaction between spermidine and pancreatic elastase. Int. J. Biol. Macromol. 2019, 131, 473-483. [CrossRef]

18. Trivella, D.B.; Dos Reis, C.V.; Lima, L.M.T.; Foguel, D.; Polikarpov, I. Flavonoid interactions with human transthyretin: Combined structural and thermodynamic analysis. J. Struct. Biol. 2012, 180, 143-153. [CrossRef]

19. Zeng, H.J.; Wang, Y.P.; Yang, R.; You, J.; Qu, L.B. Inhibitory effects of daidzein and genistein on trypsin: Insights from spectroscopic and molecular docking studies. Int. J. Biol. Macromol. 2016, 89, 336-343. [CrossRef]

20. Li, A.; Maurel, F.; Delamar, M.; Wang, B. ONIOM study of the nonbonding interaction of the 2PU inhibitor with the CDK2 and CDK4 cyclin-dependant kinases. Int. J. Quantum Chem. 2009, 109, 1148-1157. [CrossRef]

21. Lefebvre, C.; Rubez, G.; Khartabil, H.; Boisson, J.-C.; Contreras-García, J.; Hénon, E. Accurately extracting the signature of intermolecular interactions present in the NCI plot of the reduced density gradient versus electron density. Phys. Chem. Chem. Phys. 2017, 19, 17928-17936. [CrossRef] [PubMed]

22. Xiao, H.; Liu, B.; Mo, H.; Liang, G. Comparative evaluation of tannic acid inhibiting $\alpha$-glucosidase and trypsin. Food Res. Int. 2015, 76, 605-610. [CrossRef] [PubMed]

23. Stewart, J.J. Optimization of parameters for semiempirical methods V: Modification of NDDO approximations and application to 70 elements. J. Mol. Model. 2007, 13, 1173-1213. [CrossRef] [PubMed]

24. Morris, G.M.; Huey, R.; Lindstrom, W.; Sanner, M.F.; Belew, R.K.; Goodsell, D.S.; Olson, A.J. AutoDock4 and AutoDockTools4: Automated docking with selective receptor flexibility. J. Comput. Chem. 2009, 30, 2785-2791. [CrossRef] [PubMed]

25. Wallace, A.C.; Laskowski, R.A.; Thornton, J.M. LIGPLOT: A program to generate schematic diagrams of protein-ligand interactions. Protein Eng. Des. Sel. 1995, 8, 127-134. [CrossRef]

26. Lu, T.; Chen, F. Multiwfn: A multifunctional wavefunction analyzer. J. Comput. Chem. 2012, 33, 580-592. [CrossRef] [PubMed]

27. Humphrey, W.; Dalke, A.; Schulten, K. VMD: Visual molecular dynamics. J. Mol. Graph. Model. 1996, 14, 33-38. [CrossRef]

28. Xu, D.; Wang, Q.; Zhang, W.; Hu, B.; Zhou, L.; Zeng, X.; Sun, Y. Inhibitory activities of caffeoylquinic acid derivatives from Ilex kudingcha CJ Tseng on $\alpha$-glucosidase from Saccharomyces cerevisiae. J. Agric. Food Chem. 2015, 63, 3694-3703. [CrossRef] [PubMed]

29. Dolatabadi, J.E.N.; Panahi-Azar, V.; Barzegar, A.; Jamali, A.A.; Kheirdoosh, F.; Kashanian, S.; Omidi, Y. Spectroscopic and molecular modeling studies of human serum albumin interaction with propyl gallate. RSC Adv. 2014, 4, 64559-64564. [CrossRef]

30. Androutsopoulos, V.P.; Papakyriakou, A.; Vourloumis, D.; Spandidos, D.A. Comparative CYP1A1 and CYP1B1 substrate and inhibitor profile of dietary flavonoids. Bioorg. Med. Chem. 2011, 19, 2842-2849. [CrossRef] [PubMed]

31. Mahfoudi, R.; Djeridane, A.; Benarous, K.; Gaydou, E.M.; Yousfi, M. Structure-activity relationships and molecular docking of thirteen synthesized flavonoids as horseradish peroxidase inhibitors. Bioorg. Chem. 2017, 74, 201-211. [CrossRef] [PubMed]

(C) 2019 by the authors. Licensee MDPI, Basel, Switzerland. This article is an open access article distributed under the terms and conditions of the Creative Commons Attribution (CC BY) license (http://creativecommons.org/licenses/by/4.0/). 